\title{
Vecinos, patrimonio, instituciones y cuentapropistas en La Habana Vieja. Santo Ángel desde dentro*
}

\author{
Neighbors, Heritage, Institutions and Entrepreneurs \\ in La Habana Vieja. Inside Santo Ángel
}

\author{
Arantxa Ibarrola ${ }^{1}$ \\ Universidad Pública de Navarra
}

\section{RESUMEN}

Este artículo nos lleva hasta Santo Ángel, pequeño barrio de la Habana Vieja expuesto en muy poco tiempo a nuevas formas de la economía mercantil. La investigación documenta las relaciones sociales existentes entre los vecinos de siempre - y su patrimonio privado-, las instituciones públicas, los nuevos vecinos, los nuevos emprendedores, los nuevos trabajadores y los turistas internacionales y analiza el proceso de transformación social y económica desde una comunidad estable, similar y basada en el principio de reciprocidad hasta otra provisional, compleja y diferenciada.

Palabras clave: Santo Ángel (La Habana); Barrio; Patrimonio; Instituciones; Comunidad; Reciprocidad; Iniciativa privada; Mercado; Turismo.

\section{SUMMARY}

This article takes us to Santo Ángel, a little neighborhood of La Habana Vieja exposed over a short space of time to new forms of the market economy. The research documents social relationships between older residents—and their private heritage-public institutions, new neighbors, new entrepreneurs, new workers and international tourists. It also analyses the process of social and economic transformation from a stable, similar and reciprocity-based community to an uncertain, complex and differential one.

Keywords: Santo Ángel (La Habana); Neighborhood; Heritage; Institutions; Community; Reciprocity; Private Initiative; Market; Tourism.

\section{INTRODUCCION}

Numerosos autores han mostrado en los últimos años que, a la hora de analizar los procesos de puesta en marcha de nuevas organizaciones económicas, es necesa-

\footnotetext{
* Este trabajo se ha realizado en el marco del Programa de Movilidad ERASMUS + 2015-2016 y concretado en la Acción KA107 2014-2020.

${ }^{1}$ Correo electrónico: aranzazu.ibarrola@unavarra.es. ORCID iD: <https://orcid.org/0000-00015071-0447>.
} 
rio introducir perspectivas teóricas que incluyan las relaciones dinámicas entre los contextos culturales, históricos e institucionales particulares en los que se sitúan estas nuevas organizaciones y el nuevo sistema económico, mercantil y globalizado (Callon y Muniesa 2003; Karpik 2007).

Así que conocer el proceso de emergencia de la iniciativa privada en el sector turístico de un país históricamente alejado de la economía capitalista se nos presenta como la oportunidad perfecta para analizar los procesos empíricos de construcción de nuevas prácticas económicas que incorporan criterios mercantiles globales pero que atienden también a criterios culturales e históricos específicos y locales.

Dado que la realidad que vamos a estudiar presenta distintos niveles narrativos y numerosas mediaciones complejas, nos decantamos por una aproximación etnográfica que, desde nuestro punto de vista, nos va a permitir realizar análisis complejos en los que podremos reintegrar discursos particulares, narrativas institucionalizadas y acciones políticas (Latour 1993).

Para abordar todo ello, proponemos en primer lugar un marco interpretativo; en segundo lugar, veremos cómo a través de un caso de estudio —el callejón de los Peluqueros en el barrio de Santo Ángel y su proyecto Arte Corte- se articulan los discursos, los actores y las acciones ante las nuevas exigencias socioeconómicas que marcan las políticas institucionales; por último, presentaremos unas breves conclusiones.

Para producir este conocimiento nos hemos sumergido en la vida cotidiana del barrio durante varios meses consecutivos y en la de una institución concreta, la Oficina del Historiador de La Habana ${ }^{2}$. La entidad nos conecta con Arte Corte ${ }^{3}$ y su emprendedor con el barrio; desde esta posición amiga con el emprendedor tenemos un acceso inmediato a todas las instalaciones del proyecto comunitario, a los salones de los vecinos y de los representantes barriales y a los negocios de los cuentapropistas; así que desde el inicio podemos mantener fluidas conversaciones con los habitantes - estables o no- del callejón de los Peluqueros.

El uso de la entrevista situada en la interacción cotidiana — charlas practicadas de forma casual y sin ningún fin específico (Tarde 2006 [1902]) — ha supuesto el recurso principal para recoger el discurso y los puntos de vista de los informantes; nuestra intención ha sido, en todo momento, generar una situación de escucha en la que nuestros interlocutores se sintieran libres para referirse a aquello que les sugiriera el propio proceso de la conversación y no se percibieran como interrogados (Olivier de Sardan 1995). Ha habido también numerosas entrevistas formalizadas y programadas con vecinos, cuentapropistas, trabajadores y agentes institucionales con los que ya había una interacción cotidiana aunque, en realidad, el protocolo de estas comunicaciones ha sido bastante exiguo, todas ellas desarrolladas en su entorno cotidiano - hogar o lugar de trabajo- y han transcurrido en un ambiente completamente informal y desestructurado.

Simultáneamente a la realización de las entrevistas, la observación sistemática de la realidad diaria del callejón y sus alrededores se ha desvelado como un potente medio para reconocer los modos y procesos relacionales entre los distintos actores del lugar.

\footnotetext{
${ }^{2}$ Institución gubernamental responsable de la restauración integral del centro histórico de la ciudad de La Habana.

${ }^{3}$ Proyecto comunitario situado en el tramo final de la calle Aguiar, también llamado este tramo el callejón de los Peluqueros. Y tanto proyecto como callejón están dentro del barrio del Santo Ángel, ubicado en el centro histórico de la ciudad de La Habana.
} 
Además, hemos podido acceder a una voluminosa y valiosa documentación escrita y visual de muy diverso tipo; mediante su análisis hemos podido enmarcar la realidad local del barrio en la dinámica social, política y económica del país y hemos podido acceder a otros momentos del barrio que también nos han ayudado a comprender el escenario dinámico y moldeable que es el callejón de los Peluqueros en estos momentos.

\section{LA ACCION ECONÓMICA COMO PERFORMANCE TÉCNICA Y SOCIAL}

Nuestro acercamiento al barrio de Santo Ángel y su posterior análisis descansa en tres criterios epistemológicos. Primero, nada es inmutable (Tarde 2006 [1902]), así que la comunidad como concepto va a ser definida y tratada como un ente difuso, abierto y escurridizo, sin límites físicos o temporales; considerarla en su movimiento más que en su estructura permitirá ver con más claridad los procesos que la conforman. En segundo lugar, la performatividad de la acción social constituye causa y efecto de procesos en los que se articulan gente, ideas y artefactos que, en una constante negociación se (re)combinan y (re)crean de forma particular en espacios y tiempos determinados (Callon y Latour 1997). Por último, el cambio y la innovación social surgen de la interacción recurrente de numerosos y diferenciados actores, entre los que se encuentran humanos y no humanos (Callon 2001). Los objetos, particularmente el patrimonio inmobiliario privado y el espacio y mobiliario públicos en la callecita de Aguiar y, por ende, en el barrio de Santo Ángel, no se van a tratar como meras representaciones sociales sino que se incluyen en esta investigación como entes que -al igual que los seres humanos - tienen una vida que es, por supuesto, social (Kopyttof 1986).

Esta etnografía se centra, pues, en el análisis de la construcción de las redes económicas, técnicas y sociales en las que actores tan heterogéneos como turistas, cuentapropistas $^{4}$, vecinos, oficinas, patrimonio, historia, escuelas y oficios se desenvuelven, conformando modos particulares de producción y reproducción social de los miembros de la comunidad (Narotzky 2013) situada en el barrio de Santo Ángel en La Habana.

\section{EL BARRIO DEL SANTO ÁNGEL: DEL PATRIMONIO PARA LA REPRODUCCIÓN AL PATRIMONIO PARA LA PRODUCCION}

\section{EL BARRIO COMO ESPACIO REPRODUCTIVO}

En la últimas décadas del siglo XX, se dan en la Habana Vieja sucesivas llegadas de gente provenientes de otros lugares del país - y de la propia Habana- que tienen como consecuencia diversos modos de aprovisionamiento de vivienda y periódicas modificaciones de los alojamientos según las necesidades del grupo familiar, lo

\footnotetext{
${ }^{4}$ Término legal y socialmente aceptado en Cuba que equivale a las expresiones emprendedor y/o empresario.
} 
que tiene como consecuencias más evidentes el hacinamiento y una suerte de chabolismo vertical.

Sin embargo, Santo Ángel se mantiene bastante al margen de todos estos vaivenes inmobiliarios y conserva, de forma general, la estructura arquitectónica y habitacional con la que fue construido. Debido a su cercanía con el antiguo palacio presidencial $^{5}$, el barrio se convirtió en el lugar de residencia para muchos de sus trabajadores, por lo que sus calles y edificios estuvieron durante décadas protegidos y casi aislados de los barrios aledaños. Tras la Revolución de $1959^{6}$, aquellos habitantes relacionados ideológicamente con el gobierno batistiano ${ }^{7}$ huyen, aunque otros muchos permanecen y mantienen sus propiedades.

Este nuevo sistema político-social estataliza rápidamente la propiedad de los medios de producción con el fin de generar una sociedad propietaria colectivamente de estos; sin embargo, la transición hacia una propiedad social no estatal jamás se materializa y los ciudadanos terminan observándose a sí mismos como trabajadores para un Estado que planifica centralizadamente la economía (Coraggio 2013) y para un sector minoritario que ha asumido el control administrativo de los medios de producción (Torres Pérez 2015).

Este posicionamiento ideológico duro del país con respecto al modelo económico implantado (Coraggio 2013) y el persistente bloqueo económico y financiero impuesto por Estados Unidos —entre otros factores macroeconómicos—, lleva a Cuba a períodos de profundo desabastecimiento material, entre los que destaca el conocido como período especial, llamado así por Gobierno y ciudadanía, y que consiste en un tiempo de severas restricciones económico-financieras provocadas por la desaparición del bloque soviético. Y los habitantes de Santo Ángel han de ingeniárselas todos los días para obtener su sustento, ya que sus salarios son bajos y no hay circuitos estables para la circulación ${ }^{8}$ y distribución de bienes y servicios —en ciertos momentos no hay apenas bienes y servicios que circulen-.

En este contexto particular, las actividades económicas que emergen —más bien se consolidan- nacen del arraigo al entorno y de la vinculación primaria que se da entre las familias residentes. Las interacciones entre ellas, densas y cotidianas, se ven facilitadas por los siguientes motivos. El primero de ellos $-\mathrm{y}$ englobando a los demás- es el sentido de pertenencia al barrio. Afectos e inquinas, amores y desamores, nacimientos y muertes, responsabilidades y placeres — la vida en definitiva-, han transcurrido en la misma casa y en la misma calle. El segundo es la similitud que la inmensa mayoría de la gente de la calle presenta en sus condiciones socioeconómicas - tales como su desempeño productivo, su nivel de acumulación material, la propiedad y características de su patrimonio familiar-, así como en la situación histórica que les toca vivir y en la coincidencia de sus propios procesos vitales. El tercer mo-

\footnotetext{
${ }^{5}$ Residencia oficial del presidente Fulgencio Batista, presidente electo de Cuba de 1940 a 1944 y gobernante de facto entre 1952 y 1959

${ }^{6}$ Movimiento ligado a la izquierda cubana que se alza contra el régimen de Batista apartándolo del poder

${ }^{7}$ Referido al régimen de Batista.

${ }^{8}$ El concepto de distribución se refiere al proceso de asignación de bienes entre diferentes individuos o grupos, mientras que el concepto de circulación se refiere al movimiento de esos bienes.
} 
tivo es que las relaciones se basan en muchos casos en el parentesco y la estabilidad, entabladas y transmitidas por miembros de distintas generaciones; la idea de familia y parentesco no reside exclusivamente en la consanguinidad sino también en vinculaciones profundas que generaciones anteriores establecieron entre sí y que se proyectan en las siguientes (Godelier 1990 [1984]).

Vivir pues, durante décadas, en la misma cuadra y en el mismo barrio da lugar a transacciones recurrentes de todo tipo que desembocan en un conocimiento profundo y recíproco de las circunstancias específicas de cada uno de sus habitantes y de las relaciones que cada grupo familiar mantiene. Salir por estas calles supone encontrarse con otros de los que se conoce casi todo y por los que interesarse, pues uno se sabe también conocido y —en una medida u otra-cuidado. Estas tupidas redes relacionales se sustentan en el ejercicio de todas las formas posibles de distribución y circulación expresadas por Polanyi (2006 [1944]): la redistribución, el intercambio mercantil y la reciprocidad.

Por lo que respecta a la redistribución, al haber desaparecido la iniciativa privada de carácter capitalista, el Gobierno crea todo un sistema público estatal para la distribución de aquellos productos y servicios básicos para cubrir las necesidades habituales de la ciudadanía. Instaura la libreta para el aprovisionamiento de la cesta mínima alimentaria familiar y la libreta sanitaria, que permite la adquisición de medicamentos y otros productos relacionados con la salud. Este sistema redistributivo planificado tiende a disminuir todavía más la diferenciación social de las familias al reducir la presencia de la moneda y las elecciones individuales de consumo en los procesos de aprovisionamiento.

Provistos de ambos instrumentos, los vecinos del barrio pueden dirigirse a la bo$\operatorname{deg} a^{9}$ de la esquina, a la carnicería, a la farmacia y, si tienen animales de compañía, al dispensario veterinario que está un poco más allá de la bodega. Incluso disponen en la otra esquina de un bar histórico — ahora estatalizado- que facilita el encuentro y la socialización vecinal.

En cuanto a los intercambios puramente comerciales, los vecinos actúan en numerosas transacciones monetarias en las que una parte retribuye económicamente a la otra en pago por, normalmente, unos servicios realizados. Lo habitual es que estos intercambios de dinero por servicios se terminen realizando con personas vinculadas de una manera u otra al barrio y que la cuantía debida se decida de acuerdo a esa vinculación y no tanto a la oficialidad de los precios.

Y rodeando, atravesando, complementando y sustentando a la (re)distribución estatal y al intercambio retributivo, los vecinos del barrio $-\mathrm{y}$ muy probablemente la inmensa mayoría de los habitantes de La Habana Vieja - se aplican al desarrollo de una ingente masa de transacciones materiales que abarcan prácticamente todos los tipos y formas que el concepto de reciprocidad puede alcanzar, es decir, todo ese continuo de posibilidades desde el extremo de la donación sin expectativas de retorno hasta el extremo de la apropiación egoísta mediante el engaño o la fuerza (Shalins 1983 [1974]). Así, los vecinos se regalan alimentos si se encuentran por la calle a la vuelta del mercado o se dirigen a la casa más próxima para regalar una porción de comida cocinada; son habituales las invitaciones espontáneas a un café o un almuer-

\footnotetext{
${ }^{9}$ Establecimiento que distribuye los productos sancionados por la libreta de abastecimiento.
} 
zo; útiles domésticos circulan en distintos sentidos para volver finalmente a sus propietarios originales; los más hábiles reparan desperfectos en las casas de las personas más ancianas a cambio de sencillos obsequios; compran y venden todo tipo de objetos mediante precios de vecino, inferiores a los acordados con extraños y mediante pagos aplazados; los adultos conocen, vigilan -y alimentan si es necesario- a los infantes del barrio... En las narraciones de los habitantes del barrio que vivieron estos años aparece con mucha frecuencia la siguiente conclusión: "nunca un vecino se quedará sin una pastilla o un remedio" (Representante vecinal de Aguiar, entrevista personal, 19 jul. 2018) si los necesita y los otros disponen de ello. Obviamente, también emergen discursos que describen relaciones superficiales y seculares enemistades en cuyas transacciones predomina la desconfianza y la rivalidad.

$\mathrm{Y}$ en este contexto vecinal, cohesionado y familiar, uno de sus miembros vuelve al barrio y trae con él la inusual idea de montar una peluquería privada, aprovechando la apertura del Gobierno al trabajo por cuenta propia a finales de los 90 . Sin embargo, esta apertura a la iniciativa privada resulta complicada pues, tanto ideológica como culturalmente, la empresa no estatal se mira con muchas reservas (Pérez Martínez 2014) y para Papito, nuestro vecino retornado, las cosas no son fáciles al principio, con la familia y allegados reorientándolo al redil de los barberos estatales. Pero no, convencido de lo que se trae entre manos, instala los primeros sillones en lo que antes era el salón del hogar familiar y comienza a "pelar cabezas" —en sus propias palabras-, tanto las de sus vecinos como las de clientes fieles conseguidos a lo largo de sus casi 15 años de barbero estatal.

Falto de capital y sin apenas apoyo, la necesidad manda y de ella hace virtud cuando, al ir aumentando clientela debe ampliar mobiliario y utensilios; observa que muchas de las barberías estatales están cerrando y otros peluqueros están retirando o vendiendo sillones, secadores y demás útiles barberos para adquirir otros más modernos y funcionales. Estos objetos aparentemente obsoletos serán los que el joven barbero comprará. Porque son más baratos, sí, pero también y sobre todo porque todo eso que acumula polvo en barberías anticuadas y que circula como mercancía poco valiosa atesora cualidades como la belleza, los recuerdos de encuentros cotidianos o la historia de generaciones pasadas. Papito aprecia su valor simbólico y singular por encima de su valor monetario y decide caracterizar su peluquería no solo como un espacio productivo mercantil, sino también como un espacio único que favorezca la socialización y la cultura. La pequeña barbería — que podría haber sido una más, eficiente, moderna y regida por la calidad y el precio de sus productos y servicios- se convierte en una suerte de universo en el que se dan la mano el pasado y el presente, el arte y la técnica, el conocimiento y el afecto. A ella van a llegar en tropel elementos que la contabilidad mercantil jamás tiene en cuenta (Lebowitz 2012): el afecto y el orgullo que Papito siente por su oficio, los barberos de otras épocas y de otros lugares de Cuba, las amistades cultivadas a lo largo de su trabajo como peluquero estatal, su afición por la pintura o las relaciones de buena vecindad con artistas de cuadras aledañas, los cuales le regalan con gusto obras en las que, justamente, se reflejan todos esos elementos difíciles de monetizar.

Cuando las paredes ya no pueden acoger más cuadros, las imágenes se desparraman por las paredes de las empinadas escaleras hasta llegar a la puerta del edificio, y todo lo que entró en la peluquería emprende el camino de vuelta hacia la calle, transformado 
ahora en un proyecto cultural, Arte Corte, con el que Papito persigue la dignificación del oficio de barbero y de todos los objetos, saberes y procesos que lo integran.

A partir de 2002, inspirado por la filosofía practicada en la Oficina del Historiador de La Habana, Papito crea en su propio negocio el primer museo de barbería en el país y el premio Juan Gómez —uno de los primeros barberos registrados en América-, organiza festivales y conforma colecciones pictóricas sobre la peluquería, entre otras actividades. Y muchas de ellas ni siquiera rebasan los límites de la callecita de Aguiar, lugar donde reside la peluquería, aceptadas con sumo gusto por los vecinos, estos tan pronto abren sus puertas para que entren exposiciones y talleres en sus salones, como se convierten en espectadores y protagonistas de pasarelas de moda, de obras de teatro o de espectáculos musicales, todo ello sin salir de sus aceras.

En esta primera década de siglo al barrio no le va del todo bien, la población envejece y la situación económica se degrada. Bastantes jóvenes de estas cuadras tienen serias dificultades familiares y muy poco equipamiento para acceder a la vida adulta productiva, así que muchos de ellos terminan relacionándose entre sí como grupo ajeno al barrio cognitiva, afectiva y moralmente, por lo que las transacciones solidarias se reducen, si acaso, a su círculo más privado y se manejan habitualmente en el marco de unas relaciones predatorias y basadas en la jerarquía de poder (Moreno 2005). El acoso y la estafa a los turistas, el consumo y tráfico de estupefacientes u otras mercancías ilegales, los pequeños hurtos a cualquier despistado y pelear con otros grupos de jóvenes, constituyen para ellos comportamientos deseables que les vinculan a sus familiares de más edad —en ocasiones en la cárcel o muertos- y los resitúa en los márgenes sociales del barrio.

Cuando transita por las calles con sus cosas de barbero y de vecino, Papito distingue bien a esos jóvenes y se reconoce en ellos, quizás porque él mismo pasó por muchas escuelas pero en ninguna permaneció y se recuerda en algún momento de su juventud tanteando ese mundo periférico. Papito recuerda una infancia en un barrio donde las redes afectivas facilitan la vida en y de la comunidad. También medita sobre el hecho de que aprender un oficio le ha permitido a él mismo alejarse de la marginalidad vislumbrada y le ha dado un medio de sustento, por lo que considera que si les enseña el arte de la peluquería y les muestra unos valores que promueven otro tipo de relaciones al que están acostumbrados, estos jóvenes podrían sustituir sus modos de operar por otros más integradores socialmente.

Montar una escuela de peluquería comunitaria, gratuita y dirigida a jóvenes con dificultades se convierte en el sueño de Papito y va a movilizar gente y cosas para hacerlo realidad, pues desde el principio sabe que este es un proyecto de envergadura que requiere de múltiples recursos e intervenciones.

Así que, tras dos años de insistencia en la Oficina del Historiador, esta le da el permiso para ocupar un pequeño trozo del almacén del restaurante La Cabaña, de propiedad estatal; conseguidos el interés y el apoyo financiero de la Oficina, la escuelita se inaugura en septiembre de 2010.

Por lo que respecta a su equipamiento y al trabajo docente, Papito pone algo de capital, algunos objetos de su colección y, por supuesto, todo lo que ha aprendido del oficio. Sus colegas peluqueros y los artistas locales entran también de lleno en este nuevo proyecto y donan obras de arte, sillones y otros artefactos barberos, trabajo voluntario de construcción, de mantenimiento, de docencia, de orientación... 
Pero la escuela no es la única actividad social del proyecto Arte Corte, este hace tiempo que ha trascendido el ámbito barberil para dirigirse a la comunidad, sobre todo a la cuadra de Aguiar, cuyos habitantes se han ido sumando progresivamente. También los vecinos y organizaciones políticas, deportivas y culturales del barrio reconocen los fines sociales del proyecto como suyos y le aportan sus propias actividades.

Pero la convivialidad se materializa y transcurre en el medio físico - casas, edificios institucionales, comercios, calles, aceras o parques- y aquella no se sostendrá si este se deteriora y desaparece. El proyecto pues, dirige también su mirada al patrimonio.

Al inicio del barrio hay un antiguo parque infantil que se encuentra completamente desbaratado; está cerrado porque la parcela pertenece al museo de la Revolución y tiene previsto intervenir en ella, aunque no termina de hacerlo y el parquecito languidece en esa esquina, usado básicamente como espacio de encuentro y mercadeo para muchos de los jóvenes que durante el día se ven en la esquina del otro extremo del barrio.

Tras siete años de insistencia, Papito consigue por fin la licencia de uso y proyecta con la Escuela de Diseño un parque en el que todos sus elementos recuerden el oficio de la barbería; la Oficina del Historiador, por su parte, adjudica recursos técnicos y financieros para su construcción. El parque se convierte en una realidad y Arte Corte habilita dentro una minibarbería para una de las primeras alumnas de la escuela; también ayuda a otro joven a que pueda entrar un carrito con comida y bebidas no alcohólicas.

Este joven, otrora esquinero ${ }^{10}$ y usuario habitual del parquecito desbaratado, consigue pasar en poco tiempo de un carrito pequeño a un quiosco — construido con permiso y ayuda de la Oficina- dentro del propio parque, y le va tan bien que decide buscar a un antiguo compañero de correrías para que trabaje con él. Ambos, peluquera y quiosquero, mantienen limpio el parque y pagan a un viejito para que les ayude; también arreglan los pequeños desperfectos cotidianos y la Oficina, por su parte, paga a los vigilantes nocturnos y se encarga de los desperfectos de envergadura.

Por lo que respecta al patrimonio de la callecita, este no se encuentra tan arruinado como el parquecito pero sus vecinos lo encuentran bastante deteriorado y feo. Años de tránsito rodado por el lugar han dejado las fachadas negras y han deteriorado las aceras y el asfalto; por el extremo de la avenida de las Misiones el callejón está cerrado desde hace muchos años a causa de las obras de restauración emprendidas en el museo de la Música y por Peña Pobre acceden vehículos que lo utilizan como aparcamiento, lo que contribuye al deterioro general. Con edificios sin pintar y ni una sola planta que refresque y anime el ambiente, este tramo de Aguiar se convierte en un lugar muy poco favorable para el encuentro y socialización en la calle.

Aunque algunos vecinos procuran tener su fachada pintada lo cierto es que la edad y la falta de recursos dificultan a la mayoría de los vecinos el mantenimiento y cuidado de sus propiedades. Papito convoca a los vecinos y les propone adecentar con-

${ }^{10}$ Término utilizado para referirse a jóvenes presuntamente implicados en comportamientos ilícitos. 
juntamente la callecita aportando cada uno lo que buenamente pueda. El vecindario se congrega con entusiasmo alrededor de esta idea y prácticamente todos aportan dinero, tiempo, habilidades y trabajo para embellecer su lugar de residencia de toda la vida y al que le han conocido tiempos mejores. Aparecen maticas en la calle que se riegan voluntariamente con el agua de las casas, se arreglan tramos de acera, se sacan alguna mesa y sillitas para (re)colonizar el espacio invadido por los vehículos, los artistas locales regalan hermosas esculturas; se pone dinero para comprar pinturas y otros útiles y se pintan las fachadas de los edificios, aunque solo hasta la primera planta porque pintar más arriba supone un esfuerzo económico inasumible.

En cualquier caso, toda esta buena voluntad da sus frutos y la callecita muestra ahora otro aspecto, mucho más fresco y colorido..., quizás incluso demasiado. La cooperación de los vecinos ha sido casi unánime y ha permitido una actuación autogestionada dirigida a la mejora de lo común, pero desafortunadamente las operaciones concretas se han desarrollado según los gustos particulares, lo que ha dado como resultado un carnaval cromático y flagrantes violaciones de unas desconocidas normas urbanísticas que, ignorantes ellos, también les atañen porque habitan en una zona incluida en el plan de desarrollo de la Oficina del Historiador. Así que cuando este pequeño cúmulo de despropósitos urbanísticos y estéticos llega a oídos de la institución, esta se ve forzada a aparecer con una ingrata tarea: obligar a los vecinos a deshacer lo que con tanta ilusión y afecto han llevado a cabo. Sin embargo, el entusiasmo popular termina convenciendo a los técnicos de la Oficina, la cual decide adelantar su intervención en la pequeña cuadra. Decide el cambio de la pavimentación, el soterramiento de cables, la dotación de mobiliario urbano mínimo y la rehabilitación de las fachadas de los edificios en todas sus plantas, eso sí, con una adecuada paleta de color. También decide la peatonalización del primer tramo de Aguiar, la señalización alusiva a Arte Corte y la instalación temporal de toldos y otros artefactos implicados en las actividades comunitarias, consolidando al proyecto urbanística y públicamente.

Dos años después finalizan las obras y se abre el extremo de la avenida de las Misiones: la callecita se ha convertido en el flamante callejón de los Peluqueros. Y sus habitantes todavía no se lo creen, jamás habrían imaginado hasta dónde les iba a llevar apiñarse alrededor del único cuentapropista del barrio y sacar al unísono las brochas y las maticas a su calle, lugar ahora en donde se combinan arte, patrimonio y comunidad.

A partir de este momento, proyecto social y callejón ensanchan sus horizontes y emprenden nuevos caminos con compañeros cada vez más numerosos. En estos momentos, Arte Corte ya es un proyecto integral — con una directiva vecinal y todocuyos objetivos se materializan, entre otras, en las siguientes actividades:

La escuela de peluquería. Ya han salido varias promociones de jóvenes que en muchos casos tienen su negocio en otros barrios de la ciudad. Además, las aulas y el equipamiento se ceden a otras entidades relacionadas con la barbería y peluquería para sus propias acciones.

La Casa de los Abuelos. El proyecto ayuda en su mantenimiento y embellecimiento. Además, cada miércoles organiza el Disco Son, un evento musical en la calle con músicos y alumnos de escuelas de baile voluntarios.

El Comedor Social. Dirigido a ancianos con muy poco poder adquisitivo. Arte Corte interviene periódicamente aportando equipamiento y otros suministros. 
Barbeparque. El proyecto organiza los sábados actividades lúdicas y culturales para los niños en las que participan voluntariamente artistas infantiles.

Talleres para niños y adolescentes. Se desarrollan en la escuela comunitaria y tienen como fin favorecer la integración social en la vida adulta activa. Todos sus docentes son voluntarios y aportan los materiales necesarios.

Otras actividades barriales. Hay dos que destacan por su poder de convocatoria: el concurso de talentos, en el que participan todas las generaciones del barrio, ya sea como concursantes o como animadores, y el concurso de animales de compañía, al que se pueden presentar aquellos perros del barrio que carezcan por completo de pedigrí.

En cuanto al barrio del Santo Ángel, aunque carece de un valor patrimonial similar al de otras zonas de La Habana Vieja, cuenta con varios factores que facilitan su transformación de entorno residencial a entorno productivo turístico: está muy cerca del Malecón y del Paseo de Prado ${ }^{11}$ y constituye una entrada natural a La Habana Vieja, transitada habitualmente por los turistas. Es rico en historia y cultura cotidianas. En sus calles nacieron y vivieron personalidades como José Martí, Félix Varela o Cirilo Villaverde ${ }^{12}$; además, numerosos pintores, realizadores de cine y escritores del siglo XX pasaron parte de sus vidas en este lugar. La conservación de su patrimonio arquitectónico es elevada, casas y calles se encuentran en buen estado y, en el caso de nuestra cuadra de Aguiar, su peatonalización y rehabilitación integral la convierten en un reducto tranquilo y atrayente. La primera facilita el paseo, la contemplación y la conversación, la segunda permite la instalación de casas de renta, restaurantes y otros negocios atrayentes para los interesados en conocer la cotidianeidad de La Habana Vieja.

\section{EL BARRIO COMO ESPACIO PRODUCTIVO}

No cabe duda de que los habitantes de Santo Ángel han mejorado, y mucho, sus condiciones materiales de vida. En sus narraciones expresan la satisfacción que les provoca este hecho y, sobre todo, se muestran ilusionados con el futuro inmediato que, consideran, se les presenta más abundante y próspero que las últimas décadas.

La restauración que lleva a cabo la Oficina del Historiador transforma no solamente el patrimonio arquitectónico sino también la relación que los habitantes mantienen con sus propiedades privadas y con las cosas públicas. Ahora, el orgullo y sentido de pertenencia que la gente del barrio ya tenía cuando este se encontraba en mal estado se refuerza y concreta en comportamientos colectivos de cuidado y mantenimiento de lo que antaño consideraban ajeno y ahora aprecian como propiedad común y espacio identitario. Como expresa un vecino de Aguiar: "Las casas mejoradas mejoran a sus habitantes". Pero además de ver en su calle un bien colectivo, identifican ahora en su patrimonio el contexto perfecto para situar en él negocios relacionados sobre todo con el turismo. Y lo que hasta entonces había sido única y exclusivamente hogar, espacio doméstico y privado, comienza a desvelarse como potencial espacio productivo, como un medio de producción.

\footnotetext{
${ }^{11}$ Lugares emblemáticos de La Habana.

12 Político, sacerdote y escritor respectivamente. Los tres están considerados fundadores de la nación cubana.
} 
El valor económico de las casas y locales empezó a aumentar en el momento en el que comenzaron las labores de restauración, pero resulta que aquel no se ha estancado una vez finalizadas estas, todo lo contrario. Cada día vienen más personas interesadas que ofrecen cada vez más dinero por el mismo espacio.

Los vecinos vislumbran una mejoría sustancial en la calidad de vida al recibir unos ingresos impensables hace tan solo un par de años. Aunque les apene dejar el barrio al que pertenecen, saben que poder habitar una casa más grande, fresca y luminosa es una oportunidad de oro, sobre todo si no tienen los medios para arreglar en la que viven ahora.

Así que muchos de los antiguos vecinos, particularmente aquellos de más edad, emprenden el camino hacia hogares más modernos y dejan el que habitaron en manos de gente llegada de otros sitios, que van a reformarlo y transformarlo en su medio de sustento. Otros, aquellos que disponen de más medios económicos, arreglan espacios dentro de sus hogares y se convierten ellos mismos en productores, normalmente como arrendadores de habitaciones para el turismo. Y algunos otros, que disponen de espacios fuera del perímetro de su hogar, los arriendan y mantienen su propiedad principal como vivienda.

Como algunos cuentapropistas buscan en el barrio a sus trabajadores, alentados por el proyecto social, más o menos todas las generaciones tienen la posibilidad de obtener beneficio material, el cual les permite acceder a nuevos modos de aprovisionamiento y experiencias. Cambian la bodega y la carnicería por modernos comercios - ya casi nadie hace uso de su cartilla de racionamiento-; frecuentan cines y otros espacios en los que se combina la cultura, el espectáculo y el dejarse ver, festejan eventos familiares y sociales en restaurantes y cafeterías alejados del callejón..., y los vecinos que consideran la calle como una extensión de su hogar son cada vez menos. Lo cierto es que entre trabajadores impecablemente uniformados, turistas vestidos a la última y tantas mesas decoradas con gusto exquisito, resulta cada vez más difícil traspasar el umbral de casa tal cual se estaba en ella y realizar tareas domésticas sencillas o simplemente conversar, jugar dominó o cualquier otra actividad social en la que no esté involucrada la transacción mercantil.

Así que las interacciones vecinales basadas en la reciprocidad y la redistribución se van reduciendo porque se dejan de usar los espacios que las propiciaban. El aumento del poder adquisitivo les ha abierto la vía a un estilo de vida más individualista y en el que las relaciones con los otros descansan más en el consumo privado y de pago.

Y aparece otro efecto inesperado de la restauración: las nuevas y mejoradas condiciones materiales están provocando la diferenciación social entre los vecinos, en otro tiempo tan similares en todas sus características.

Aquellos que se mantienen el barrio y no se benefician de la mejoría económica que la llegada de cuentapropistas y turistas ocasiona, observan cómo sus casas reflejan sus dificultades financieras; sienten la soledad de la bodega y de la carnicería y pocos ya se regalan dulces caseros o se piden la sal, al menos en la calle; además, se manifiestan incapaces de acompañar a los otros en el devenir de sus vidas, celebradas en hogares mucho más lujosos que el propio o en sitios donde hay que pagar para participar. Y los hay también que dicen no estar dispuestos a comprometerse con este nuevo estilo de vida que les rodea de extraños — negocios y turistas- y los aísla de los vecinos que quedan. 
Asistimos a un sutil y paulatino proceso de gentrificación en el barrio. Los vecinos que ven cómo desaparecen los espacios y procesos igualatorios, los que no pueden reformar sus casas e incorporarse a hábitos sociales mercantiles o los que siguen conectados a una idea de barrio popular, se marchan dejando paso a otros habitantes que traen consigo dinámicas sociales más breves y tendentes hacia el anonimato.

Y más de 15 años después de que Papito llegara, aparecen nuevos cuentapropistas en el barrio con negocios dirigidos fundamentalmente al turismo, a la cultura y al ocio. En muy poco tiempo se diseminan nuevos negocios a lo largo del callejón de los Peluqueros: estudios de pintura vanguardista y cotidiana, restaurantes exquisitos, una cafetería cinéfila, una pequeña tienda de artesanía, un estudio de fotografía, una tienda de ropa, una pequeña pizzería y, en las alturas, habitaciones de renta, arregladas por los propietarios dentro de su hogar y ofertadas a los turistas. Para montar un restaurante turístico, sin embargo, ya se requiere más capital y apenas hay vecinos que puedan acometer una inversión de este tipo, son de otros barrios de la ciudad los que compran o alquilan para, posteriormente, reformar sustancialmente la propiedad adquirida. En cuanto a los estudios de arte y las tiendas de artesanía, la inversión económica va de acuerdo a las posibilidades y expectativas del cuentapropista.

Y aquí están los emprendedores y los turistas con sus cosas: las terrazas de sombrillas, los expositores, las plantas y las papeleras, el trajín de los paseantes, los camareros, los músicos y los estudiantes. Para un vecindario tradicionalmente residencial, este repentino despliegue de modernidad alcanza visos de invasión en forma de malos olores, ruidos intempestivos y conversaciones altisonantes. Comienzan los conflictos entre los vecinos de la cuadra, sobre todo entre aquellos que viven en bajos, y los negocios. El vecindario se queja de su situación y pretende la intervención de las instituciones oficiales —incluida la policía-. El proyecto social intermedia entre instituciones y vecinos, recupera ese espíritu comunitario prepeatonal y en la escuela de peluquería — espacio común por antonomasia en la cuadra- comienzan a reunirse periódicamente organismos locales, vecinos y emprendedores para solventar internamente cualquier problema de convivencia que pueda surgir, ya sea un sistema de ventilación roto, una música demasiado alta o unas sillas dispersas.

Además, Papito propone a los cuentapropistas una asociación informal que aceptan unánimemente. Cada mes aportan una cantidad de dinero que se destina a la limpieza y conservación de los espacios públicos y de aquellas obras de arte antaño donadas, y que forman parte del paisaje urbano mucho antes que sus negocios; y si los organismos locales promueven alguna actividad en la cuadra junto con el proyecto social y los vecinos, también los emprendedores participan en mayor o menor grado de dichas actividades.

\section{LA CONSTRUCCION SOCIAL DE LA NUEVA ACCION ECONÓMICA EN SANTO ÁNGEL: ACTORES Y PROCESOS}

\section{EL EMPRENDEDOR: PAPITO}

Cuando monta su negocio de barbería allá por 1997, además de ganar el sustento de su familia, Papito busca en su trabajo autonomía de acción, disfrute y el desplie- 
gue de sus capacidades (Lebowitz 2012), intenciones todas estas al mismo nivel que la búsqueda de beneficio económico y que le llevan a desarrollar un trabajo - y por extensión un modo de estar en el mundo- alejado de la rutina y de las convenciones establecidas socialmente (Schumpeter 1976).

Aunque, lógicamente, asume tareas de trabajador y gestor de su empresa - calcula costos, pone precios a sus servicios y productos, se promociona... - se muestra un tanto irracional al descuidar el crecimiento ilimitado de su barbería y de sus beneficios y mezclar la barbería con sus aficiones, gustos y experiencias vitales, la eficiencia barberil con sus sentidos estético y social; se aleja de los comportamientos preconizados por la economía clásica al no perseguir la maximización de los beneficios empresariales, más bien desea alcanzar una posición social sólida y prestigiosa en su comunidad (Schumpeter 1976) y lo hace mediante la persistencia y la intuición, con ellas actúa creativamente y sortea esas normas institucionalizadas que ordenan que todo acto de innovación empresarial sea el resultado de procesos rigurosos, largos y teñidos de conocimiento experto y académico.

Hay una anécdota que ilustra bastante bien lo dicho hasta el momento. En 2007 el proyecto Arte Corte es seleccionado por la UNESCO y es invitado a una convención internacional sobre Patrimonio y desarrollo local en Oaxaca, México. Hasta allí viajan dos directores de la Oficina y Papito. En la aduana ningún miembro de la institución tiene problemas para pasar, pero Papito resulta extraño - y por ello sospechoso-, así que se lo llevan a unas dependencias para dilucidar qué hace un peluquero entre historiadores de prestigio. Solo cuando enarbola la presentación institucional, las autoridades mexicanas se ven obligadas a incluirlo en la categoría de experto.

Pero Papito no es un ser solitario y enfrentado al mundo, no es un inventor inadaptado y aislado que se centra en creaciones imposibles de entender e inútiles. Todo lo contrario, es un ser social situado en una madeja relacional amplia y densa que le enseña el pasado, le permite transformar el presente y le muestra futuros posibles. Este atípico empresario, en lugar de centrarse en diseñar nuevos y estilosos cortes de pelo que le aumentarían la clientela y por tanto el beneficio - lo que habría sido perfectamente racional-, se dedica a montar exposiciones, a participar en convenciones y a soltar desconcertantes declaraciones acerca del oficio de peluquería como enlace entre generaciones, como elemento cultural elegante y prestigioso, como palanca para la cohesión social y como motor económico de la comunidad, casi nada. Y diaria y machaconamente va creando opinión y testando la factibilidad de sus ideas (Akrich, Callon y Latour 1988).

Simultáneamente, caracteriza su barbería incorporando no solamente el valor económico —utilidad, eficiencia, beneficio- sino también valores como el de la belleza, la cultura o la sociabilidad (Tarde 2006 [1902]) y, una vez configurada como un espacio cultural, sale a la calle a ganar para la causa a todos aquellos que pueden decidir el fracaso o el éxito de su empresa —decididamente social y no solo empresarial- (Callon 1998). Papito sabe que tiene que captar el interés de las instituciones de gobierno, de las empresas estatales, de los organismos de acción populares, de los vecinos, de otros emprendedores..., porque todos ellos cumplen su papel en el proceso continuo de dotar de realidad a su proyecto. Este es el secreto de su éxito: actuar dentro de sus propias redes y promover la adhesión voluntaria y estable de personas e instituciones con capacidad para interactuar, negociar y dar forma a cada 
proyecto. En suma, quiere transformar el mundo y empieza por su cuadra, microcosmos que él conoce profundamente y al que arrastra energías y entusiamos heterogéneos que van conformando un proyecto cada vez más fuerte.

ARTE CORTE, EL PROYECTO SOCIAL

Shalins (1983 [1974]) afirma que es la escasez y no la abundancia lo que hace generosa a la gente y, sobre todo, es la moral del parentesco y la proximidad física lo que lleva a los grupos a ser altruistas.

En el caso del callejón, estas tres condiciones van de la mano durante muchos años y terminan conformando una tupida red de relaciones que sitúa —a casas, sujetos y familias - en una realidad física y social similar pero que simultáneamente les diferencia, les posiciona con respecto a los otros y les otorga, en última instancia, identidad (Weiner 1992).

El principio de reciprocidad amplia ha sido y es una forma de integración (Polanyi 2006 [1944]) muy frecuente entre el vecindario y, como acción colectiva e institucionalizada que es - no un mero agregado de conductas individuales-, regula las relaciones vecinales reduciendo la aparición de conflictos y afianzando las relaciones próximas (Coraggio 2011). Y el proyecto nace porque Papito ha vivido esta pauta cultural con familiares y vecinos de más edad. Casi a diario, emerge en la narrativa de este habitante del barrio una misma reflexión: si toda una comunidad le ayudó a crecer, ahora considera un deber moral ayudar a los que quizás no han tenido unos ejemplos similares.

Esta es la principal característica del proyecto Arte Corte que lo hace, justamente, social: el refuerzo de esa tupida madeja que es la relación vecinal. Densificar todavía más los vínculos establecidos es reforzar la cohesión social y el sentido de pertenencia a una comunidad; parafraseando a una vecina de Santo Ángel: "saberse de otros es preocuparse por ellos, pues también son un poco propios". Así que las acciones se encaminan al beneficio colectivo. La escuela de peluquería no busca egresados ambiciosos en pos de la riqueza y fama individuales, sino formar barberos cualificados y comprometidos; el parquecito facilita el sustento a dos personas además de la recreación de las familias y las mesas y sillas colectivas que van de un sitio a otro de la cuadra y que están disponibles para cualquiera que desee estar un rato allí sentado, no sirven solo como descanso momentáneo y para puntuales conversaciones, en realidad constituyen uno de los últimos medios para la (re)colonización de la calle y la consolidación de los vínculos sociales por parte de sus habitantes sin que esté involucrada la transacción monetaria.

En fin, toda la filosofía del proyecto descansa en la incrustación de actividades mercantiles y no mercantiles dentro de ese complejo tejido de afiliaciones y otras relaciones que es el barrio de Santo Ángel. ¿Cómo se materializan todas estas acciones? Ya hemos señalado que Papito invierte una gran parte de su tiempo en conseguir la adhesión de otros muchos, la cual se manifiesta sobre todo en la buena voluntad y el trabajo. Las acciones se sustentan en la voluntariedad y en la reciprocidad, no en la expectativa de retribución dineraria; en cuanto al trabajo, este prima sobre cualquier otro recurso y se desdobla en conocimiento puesto a disposición de los otros 
mediante su uso y/o transmisión y en las capacidades concretas que se poseen, que se usan y se combinan con otras complementarias. En ningún caso se otorga al trabajo realizado valor de cambio. También las personas aportan capital para que las actividades resulten de calidad, pero siempre transformado en productos concretos para uso de los participantes. Y vecinos, cuentapropistas y empresas estatales ceden sus propiedades para uso colectivo y conciben entonces sus casas como bienes de uso común y no como mercancías (Kopytoff 1986).

Pero el proyecto no constituye la suma de conductas individuales regidas por una moral privada. Si se puede construir es porque está situado en un contexto previamente configurado y compuesto por una serie de normas legales, concepciones culturales y esquemas de acción que se presentan ante los participantes en Arte Corte como instituciones (Crawford y Ostrom 1995), materializadas en este caso en organismos de gobierno y planificación de muy distinto signo. Nada de todo esto vería hoy la luz sin la Oficina del Historiador y sin su Plan Maestro ${ }^{13}$, cuya autoridad y filosofía perfilan el proyecto comunitario y el propio barrio; es un intermediario ineludible pues dispone del control jurídico, administrativo, financiero y operativo para definir una realidad u otra.

Arte Corte sabe que son las instituciones públicas las que han conformado los distintos espacios económicos y sociales del barrio, es el Estado el que dentro de su gobernanza y de su sistema de redistribución, mantiene la casa de abuelos, el comedor social, el parque infantil o los negocios estatales, por lo que las acciones del proyecto se definen como complemento y, si acaso, mejora de lo que ya existe, entendiéndolas siempre en un sentido social.

Las acciones ideadas por el proyecto buscan dignificar la cultura local y equipar cognitiva, moral y socialmente a sus participantes. El aprendizaje grupal y lúdico se presenta como un posible acceso a la vida adulta y activa que permitirá la creación —o búsqueda- de un modo de sustento y un modo de estar en el mundo; la realización colectiva de pequeños actos domésticos y afectivos suponen un reconocimiento del otro como igual y próximo; y, en general, la promoción de actividades cotidianas con significado propio y común favorece el arraigo y sentimiento de pertenencia al barrio.

Y he aquí la segunda característica que define a Arte Corte: es puro proceso. En realidad son incontables e incansables procesos de negociación, construcción, transformación, modificación, redefinición, actuación..., en los que todos sus protagonistas —y son muchos— se desempeñan coordinadamente (Hutchins 1995). El proyecto propone realidades posibles y propugna alianzas elásticas, flexibles y en permanente formación, entre gente diversa e instituciones diferentes cuyo trabajo conjunto se concreta en un modo particular — y no otro- de dichas realidades (Godelier 1990 [1984]).

Pero podemos observar en su evolución que el proyecto consolida la figura de la Junta $^{14}$ y contrata especialistas, sentando las bases para una estructuración organizativa

\footnotetext{
${ }^{13}$ Programa para la rehabilitación del patrimonio cultural y urbano en el barrio La Habana Vieja.

${ }^{14}$ La Junta nace del propio proyecto Arte Corte y tiene como función evaluar, replanificar y decidir sobre las actividades que el proyecto lleva a cabo. En sus inicios estuvo compuesta por cuatro miembros (el propio Papito, un vecino voluntario - abogado—, un trabajador del proyecto -economista- y un representante político-comunitario). En el momento de la etnografía, el representante político lleva tiempo sin asistir a las reuniones y trabajan en ellas solamente los tres primeros miembros.
} 
en la que se pueden apreciar indicios de nuevos modos de operar que están transformando la vinculación que mantiene con el resto de actores, particularmente con el vecindario, ante el que parece ir perfilándose más como organización institucionalizada que como proyecto comunitario. Ni Junta ni trabajadores son los propietarios de los medios de producción que distintas instituciones y empresas estatales han ido poniendo a disposición de Arte Corte, pero sí son los que proyectan nuevas acciones, buscan los recursos necesarios para llevarlas a cabo y coordinan y ejecutan el proceso de puesta en marcha de las mismas.

A los trabajadores se les define como tales porque desempeñan sus tareas a cambio de un salario, pero ese salario no resulta de la ejecución del proyecto porque todo el capital que se aporta se transforma en espacios, materiales y saber hacer; los trabajadores perciben sus ingresos de los excedentes del museo barbería y el propietario de dicha barbería es miembro de la Junta y fundador del proyecto. Esta situación favorece la independencia del proyecto ante las instituciones y otros benefactores que le ceden recursos, pero favorece su dependencia de una empresa privada y de los criterios solidarios que posea su propietario. Es la situación que más o menos ha tenido hasta la fecha, Arte Corte como el resultado de una empresa socialmente responsable que ha sabido generar relaciones estratégicas con el Estado y el sector privado (Betancourt y Sagebien 2013).

Y podemos apreciar que, cada vez más, el proyecto se organiza como una estructura productiva y, actúa como tal, es decir, se va concentrando en las acciones más exitosas dentro del sector turístico y para las que dispone de los recursos suficientes. Los trabajadores, particularmente, manifiestan su preocupación por mantener y consolidar las acciones, las cuales constituyen el corazón de la organización y son las que les procuran el salario, erigiendo su realización en el fin último de Arte Corte.

Asistimos, pues, a la transformación de un proyecto comunitario hacia un proyecto filantrópico, que redistribuye los recursos de los más prósperos hacia los más necesitados mediante un plan de acción estable y decidido, en última instancia, por una única empresa (Coraggio 2011). Y, a juzgar por el discurso de los especialistas contratados -favorables a la introducción de la economía de mercado en la economía estatalizada cubana- es probable que estemos asistiendo a su devenir en una suerte de mini-Oficina del Historiador si Arte Corte convierte a la Oficina en su asociado principal y se rige por el rol que en los últimos años le ha asignado esta última: el interlocutor privilegiado, casi único, del barrio. Concebido como pseudoinstitución puede actuar de acuerdo a negociaciones y decisiones tomadas de arriba a abajo y reducir la influencia de los vecinos en los procesos de toma de decisiones, convirtiéndolos en meros beneficiarios.

\section{LOS CUENTAPROPISTAS}

Desde la esquina de Peña Pobre hasta la esquina del bar Lucero se pueden observar más de 12 negocios particulares, además de la escuela de barbería y de las dos empresas estatales. En un cálculo aproximado, casi cien personas -entre cuentapropistas y trabajadores- producen diariamente en un tramo que probablemente 
no supere los 200 metros de recorrido, y eso sin contar todos los negocios que se han ido abriendo por las cuadras aledañas, sobre todo en la loma del Ángel ${ }^{15}$.

Aunque la apertura de negocios se ha debido sobre todo a la mejora del primer tramo de Aguiar, muchos de estos emprendedores están vinculados de un modo u otro al barrio y todos desean un lugar en una zona con historia, así que cuando construyen sus negocios lo hacen con mimo y resituando dentro de ellos mucho de lo acontecido en los espacios que reforman. Los vecinos de toda la vida reforman sus casas para ofertar al turista no solo un alojamiento o un menú sencillo, sino también una ventana - aunque sea pequeña- a la vida cotidiana de los habaneros. Y los que no son del barrio de siempre suelen ofrecer - principalmente al turista pero también a otros cubanos- parte de su historia familiar y de la cultura de La Habana.

Los primeros que llegan a la cuadra presentan una notable vinculación con Papito y sus principios; quizás porque conocieron el proyecto en sus inicios o quizás porque conocieron la cuadra gracias al proyecto, el caso es que operan de forma similar a como lo hace la peluquería y derivan parte de sus beneficios y de su tiempo a la realización de actividades culturales para los vecinos. Los que se incorporan más tarde conocen bien el proyecto pero no participan en él activamente, aunque se suelen sumar a las actividades callejeras. Y todos se incluyen dentro de esa asociación informal de emprendedores que tiene como fin el cuidado y mantenimiento del patrimonio urbano y de la tranquilidad del callejón. Su buena voluntad se manifiesta en el respeto a las quejas y recomendaciones de los vecinos — que de este modo participan en la caracterización progresiva de los negocios (Callon y Muniesa 2003) - y en la propia relación con los otros productores, con los que intercambia recomendaciones, suministros e informaciones valiosas.

Aunque en un principio los cuentapropistas contratan entre los habitantes del barrio, la necesidad de ciertas cualificaciones les lleva a emplear en su mayoría a personas que ni son de, ni habitan en el barrio; pero hay un hecho imprevisto que favorece la vinculación de cuentapropistas y empleados al entorno: sus largos horarios. En las horas más tranquilas se socializan con gente de otros negocios y del vecindario, por lo que han llegado a establecer transacciones habituales de buena vecindad en las que se intercambian experiencias, conocimientos y expectativas.

En suma, emprendedores y trabajadores trascienden las meras transacciones laborales entre sí y con el vecindario; reasignan valores relacionales a su actuar económico y lo integran en una experiencia ampliada pero, lógicamente, los cuentapropistas manifiestan que seguirán allí solamente si sus negocios les resultan rentables, y los trabajadores expresan esa misma idea: solamente se mantendrán en el lugar si mantienen su empleo. Su pertenencia al barrio es, pues, pasajera, aunque desde luego no tanto como la de los numerosos turistas que comienzan a llegar cuando la callecita se rehabilita.

El barrio muestra en su justa medida lo que el turista occidental (Cohen 1988) busca cuando viaja — particularmente cuando lo hace a un país que no se sitúa dentro del llamado primer mundo-: la autenticidad. Cosa esta concebida, paradójicamente, como un lugar sin turistas en donde la gente vive sin separar el tiempo productivo y el tiempo social y llevando a cabo prácticas culturales propias, locales y ancestrales (Shepherd 2002).

${ }^{15}$ Cuesta cercana a la calle Aguiar que desemboca en la plaza que contiene la iglesia que da nombre al barrio. 
Santo Ángel, con sus pequeños comercios de proximidad, con su historia menu$\mathrm{da}$, con su patrimonio modesto pero vivo y cuidado, y con sus vecinos cuya vida transcurre - al menos en un primer vistazo - apaciblemente y sin apenas relación con el turismo, posibilita al turista la vivencia de la cotidianeidad habanera sin los tumultos turísticos de otras partes de La Habana Vieja.

Y los vecinos del barrio - $-\mathrm{y}$ no vecinos- saben que el turismo puede suponer una oportunidad para ser más prósperos, para vivir mejor, así que están dispuestos a compartir con esa gente de efímera estancia parte de su cultura mediante la mercantilización de sus modos de estar en el mundo y de su patrimonio. Ahora, ya como productores, van a (re)producir esa vida cotidiana para los turistas, los cuales podrán vivir con una familia habanera una noche o dos en una de sus habitaciones, podrán degustar los alimentos cubanos, podrán conocer cómo viven los vecinos participando en sus costumbres y podrán adquirir hermosas fotografías, bellos cuadros o artesanías delicadas.

Sin embargo, esta (re)producción no puede ser literal, la cotidianeidad se debe (re)crear atendiendo a lo que el imaginario de los turistas les dice qué es y qué no es lo auténtico en La Habana. Los productos y los servicios ofrecidos deben reflejar la autenticidad y el significado buscados por los turistas - los cuales no suelen coincidir totalmente con la realidad actual de los vecinos ni con el significado que estos le otorgan- y presentarse de acuerdo al estilo de vida de los turistas para poder ser comprendidos y deseados (Callon y Muniesa 2003).

Los restaurantes para turistas ofrecen lo mismo que lo que hacen las cafeterías estatales y otras particulares, solo que configurado de forma distinta. En los restaurantes turísticos se procura ofrecer música cubana tradicional en vivo, mientras que en los dirigidos a los autóctonos la música televisada o enlatada nada tiene que ver con el son y además resulta atronadora —desde la perspectiva de un turista, claro está-; los alimentos de los restaurantes dirigidos a los locales suelen resultar tan seguros como los ofrecidos en los turísticos - en muchos casos más sabrosos e infinitamente más baratos- pero los turistas desconfían; y, por último, los turísticos tienden a situarse en un universo colonial de tiempo lento y ocioso, frente a la modernidad rápida y plastificada que es la hostelería para cubanos.

Por lo que respecta a artesanos, músicos, fotógrafos o pintores, producir para el turista implica la deriva de una parte de su expresividad artística hacia un -podríamos decir- costumbrismo simplificado, lo que da como resultado hornear casi industrialmente diminutos almendrones ${ }^{16}$, interpretar un día sí y otro también las canciones de Carlos Pueblas ${ }^{17}$, fotografiar desde todos los ángulos a los devotos de la Virgen de Regla y acuarelar una y otra vez la Catedral.

Los cuentapropistas del callejón no son ajenos a esta realidad y si el turista va a ser su cliente principal su oferta debe acomodarse, en mayor o menor medida, al universo imaginado por este. Y esto de la medida es la clave para generar un espacio productivo caracterizado de una forma u otra en el callejón - $-\mathrm{y}$ por ende en el resto de las cuadras del barrio-.

\footnotetext{
${ }^{16}$ Taxis colectivos de La Habana e iconos turísticos.

${ }^{17}$ Cantautor cubano, afín a la revolución de 1959.
} 


\section{CONCLUSIONES}

El callejón se ha embarcado en una complejísima tarea de reorganización de sus vínculos sociales y económicos y, en este proceso (re)organizativo de sus modos de producción y de reproducción, todos los actores intervinientes actúan de acuerdo a determinados principios éticos y económicos ${ }^{18}$ (Coraggio 2011) que subyacen en toda acción productiva, ya sea esta mercantil o no. Cada grupo de actores, y dentro de ellos cada sujeto, posee unos valores determinados que orientan sus prácticas económicas y las relaciones que de ellas se derivan; por ejemplo, observamos que la ética de los cuentapropistas no suele ser la misma que la de sus trabajadores o que la de las instituciones. Y la ética de los vecinos más pudientes metidos a productores se diferencia de la de los vecinos más apegados a un barrio exclusivamente residencial.

Entre los productores turísticos se puede intuir una ética de la reproducción del capital privado, con principios y valores competitivos, combinada con una ética de la responsabilidad comunitaria, de tal forma que observamos tanto interacciones soportadas por los intereses individuales de sus participantes como transacciones cooperativas con los otros negocios.

Por lo que respecta a la producción y la propiedad de los medios de producción, vemos que en el barrio están apareciendo numerosos modos de producción. En algunos casos, la propiedad y control de los procesos de trabajo se encuentran en manos de familias que siguen viviendo en las cuadras de Santo Ángel, en otros, la propiedad de los medios de producción es particular, lo que implica la aparición de trabajo dependiente de los propietarios.

Todos estos modos de producción se articulan, por el momento, de forma mayoritaria mediante el principio de cooperación. No obstante, y de acuerdo a los principios éticos de cada productor en particular, están surgiendo diversos modelos o formas de propiedad — como la cooperativa, pero también la sociedad anónima- y diferentes formas de participación, de empleadores y empleados, en la gestión del negocio y en el acceso al beneficio.

En cuanto a la relación con el entorno, los productores turísticos describen al vecindario como un recurso económico aprovechable, ya sea como propietarios, como muestra de estilo de vida para atraer a sus clientes turistas, como trabajadores prescindibles o como nuevos consumidores individualistas; sin embargo, también identifican a los vecinos como la red que sustenta su empresa y, por tanto, los conciben como uno de los fines de su producción. Evidentemente, los vecinos también se relacionan con las empresas desde su propia ética y del mismo modo que observan a los cuentapropistas como una oportunidad para obtener beneficios de él, los ven también como un miembro de la comunidad con el que relacionarse cotidiana y afectivamente.

Por lo que respecta a la redistribución y a la circulación de los excedentes, tanto cuentapropistas como arrendadores optan por distintas formas de distribución según su ética particular. En ocasiones, les guía el interés particular y de acumulación y,

\footnotetext{
${ }^{18}$ Se utilizan los principios de integración social de los procesos de producción, distribución, circulación y consumo propuestos por Coraggio (2011) como un esquema heurístico para la investigación de las sociedades contemporáneas.
} 
discretamente, insinúan que parte del beneficio obtenido queda sin declarar. Pero también, además de con sus impuestos, dedican parte de los beneficios obtenidos - sea cual sea la vía de consecución- y/o parte de su tiempo no productivo a sustentar la cohesión social en el barrio.

En cuanto al principio de reciprocidad, también actúan de formas diversas, bien de manera individual y filantrópica, bien colectivamente para reivindicar y disfrutar derechos, cultura, conocimiento... (Laville, en Coraggio 2011). Y con respecto al principio de intercambio, se desplazan desde el intercambio de bienes y servicios de acuerdo a un precio beneficioso para todas las partes y amparado en la costumbre hasta la oferta de bienes y servicios de acuerdo a un sistema de precios fluctuante y en el que la necesidad del otro se ve como la oportunidad para la ganancia máxima individual. Por lo que respecta al consumo, los habitantes de Santo Ángel se deciden cada vez más por un estilo privado, ilimitado e individual, aunque todavía mantienen ciertos tipos de consumo accesibles y colectivos que permiten la satisfacción de las necesidades legitimadas socialmente y que, por tanto, favorezcan la cohesión social (Coraggio 2011).

Por último, al atender a los modos de coordinación observados, nos reencontramos con el proceso del que hablábamos antes, pues Aguiar está definiendo desde dentro un modo particular y nuevo de (re)organizar todas las formas posibles de integración social (Polanyi 2006 [1944]), incluida la del mercado. El proyecto Arte Corte y su fundador - con sus primeras decisiones y actuaciones- suponen un espacio físico y simbólico reconocido y aceptado por todos los actores sociales que componen el callejón. Decidir y planificar un sistema particular de coordinación es un proyecto esencialmente deliberativo (Polanyi 2014 [1957]) que requiere de la participación consciente de gente e instituciones en procesos decisorios y de definición.

En el microcosmos que es el barrio, se dan en una medida u otra todas las combinaciones posibles de los principios señalados más arriba, y en ellas participa gente que viene y va y que se relaciona entre sí de muy diversos modos; gente que desempeña, casi siempre simultáneamente, numerosos y diferentes papeles y que mantiene innumerables transacciones con instituciones y llegados de otros mundos, que también entran y salen cotidianamente del barrio.

No es posible pues, ver a Santo Ángel como un mundo estático, homogéneo y aislado en el que la economía de mercado aparece de forma secuenciada y separada de otros ámbitos sociales. Los factores históricos, económicos y políticos se nos muestran como elementos activos e influyentes en el proceso de introducción de la ideología capitalista en la economía cubana y configuran un modo particular de materialización del mercado globalizado.

Para concluir, creemos que el estudio confirma algunos de los nuevos enfoques en antropología económica (Hann y Hart 2011; Moreno 2011; Narotzky 2013), como es, por una parte, la conveniencia de analizar los modos locales de la economía insertando en el análisis aspectos que no se han trabajado habitualmente: el espacio y el tiempo, es decir, los procesos históricos y las relaciones que esos mundos locales mantienen con otros espacios más amplios. Y, por otra, la conveniencia de estudiar las formas en que se articulan la política y la economía en diferentes niveles sociales en un contexto concreto y dinámico.

En este sentido, etnografiar el barrio del Santo Ángel nos ha permitido conocer in situ alguno de los procesos y modos de cambio de uno de los últimos países en 
los que predomina el modelo socialista, y al que la mayor parte de sus habitantes denomina como capitalismo del estado. Y este conocimiento ayuda a comprender mejor cómo las sociedades actuales se desenvuelven combinando la burocracia estatal con la presencia cada vez más preponderante del capital y del mercado en ellas.

\section{BIBLIOGRAFIA CITADA}

Akrich, Madeleine, Michel Callon y Bruno Latour. 1988. "A quoi tient le succès des innovations? 1: L'art de l'intéressement, Gérer et comprendre". Annales des Mines 11: 4-17.

Betancourt, Rafael y Julia Sagebien. 2013. "Para un crecimiento inclusivo: empresas no estatales en Cuba". Temas. Cultura, ideología y sociedad 75: 58-66.

Callon, Michel. 1998. "Introduction: The Embeddedness of Economic Markets in Economics", en Michel Callon (ed.), The laws of the markets: 1-57. Oxford: Blackwell.

Callon, Michel. 2001. "Redes tecno-económicas e irreversibilidad". Redes 8(17): 85-126.

Callon, Michel y Fabian Muniesa. 2003. "Les marchés économiques comme dispositifs collectifs de calcul". Réseaux 122(6): 189-233.

Callon, Michel y Bruno Latour. 1997. "Tu ne calculeras pas!" ou comment symétriser le don et le capital. Revue du MAUSS 9: 45-70.

Cohen, Erik. 1988. "Authenticity and Commoditization in Tourism". Annals of Tourism Research 15: 371-386.

Coraggio, José Luis. 2011. Economía social y solidaria. El trabajo antes que el capital. Quito: Flacso.

Coraggio, José Luis. 2013. "Tres corrientes en la ESS". Temas. Cultura, ideología y sociedad 75: 4-12.

Crawford, Sue E. S. y Elinor Ostrom. 1995. "A Grammar of Institutions". American Political Science Review 89(3): 582-600.

Godelier, Maurice. 1990 [1984]. Lo ideal y lo material. Pensamiento, economias, sociedades. Madrid: Taurus.

Hann, Chris M. y Keith Hart. 2011. Economic Anthropology: History, Ethnography, Critique. Cambridge: Polity Press.

Hutchins, Edwin. 1995. Cognition in the Wild. Cambridge: The MIT Press.

Karpik, L. 2007. L'économie des singularités. París: Gallimard.

Kopytoff, Igor. 1986. "The Cultural Biography of Things: Commoditization as Process", en Arjun Appadurai (ed.), The social life of things: commodities in cultural perspective: 64-91. Cambridge: Cambridge University Press.

Lebowitz, Michael. 2015. La alternativa socialista. El verdadero desarrollo humano. La Habana: Ciencias Sociales.

Moreno, Paz. 2005. "Organizar: suspensión de la moralidad y reciprocidad negativa", en Paz Moreno Feliú (comp.), Entre las Gracias y el Molino Satánico: Lecturas de Antropología Económica: 375-402. Madrid: UNED.

Moreno, Paz. 2011. El bosque de las Gracias y sus pasatiempos. Raíces de la antropología económica. Madrid: Editorial Trotta

Narotzky, Susana. 2013. "Introducción", en Susana Narotzky, Economías cotidianas, economías sociales, economias sostenibles: 7-25. Barcelona: Icaria.

Pérez Martínez, Yuri. 2014. Fundamentos jurídicos para la armonización de intereses públicos y privados en sede de alojamiento turístico en Cuba. Tesis doctoral. Universidad de La Habana.

Polanyi, Karl. 2006 [1944]. The Great Transformation. The Political and Economic Origins of Our time. Boston: Beacon Press.

Polanyi, Karl. 2014 [1957]. "La economía como actividad institucionalizada", en Karl Polanyi, César Rendueles Menéndez de Llano y Isidro López, Los límites del Mercado. Reflexiones sobre economia, antropología y democracia: 187-214. Madrid: Capitan Swing.

Shalins, Marchall. 1983 [1974]. Economía de la Edad de Piedra. Madrid: Akal.

Shepherd, Robert J. 2002. "Commodification, culture and tourism". Tourist Studies 2(2): 183-201. 
Schumpeter, Joseph A. 1976. Teoría del Desenvolvimiento Económico. México: Fondo de Cultura Económica.

Tarde, Gabriel. 2006 [1902]. Psychologie économique. Edición facsímil electrónica de la Universidad de Quebec en Chicoutimi. Disponible en: <http://classiques.uqac.ca/classiques/tarde_gabriel/ psycho_economique_t1/psycho_eco_t1.html http://classiques.uqac.ca/>. Fecha de acceso: 29 jun. 2018.

Torres Pérez, Ricardo. 2015. "Un nuevo modelo económico en Cuba: el rol del sector privado", en Omar E. Pérez y Ricardo Torres (eds.), Miradas a la economía cubana. Análisis del sector no estatal: 15-26. La Habana: Editorial Caminos.

Weiner, Annette B. 1992. Inalienable Possessions: The Paradox of Keeping While Giving. Berkeley: University of California Press.

Fecha de recepción: 26 de enero de 2017

Fecha de aceptación: 22 de marzo de 2018 